\title{
Supercontinuum generation in photonic crystal fibers: The role of the second zero dispersion wavelength
}

Frosz, Michael Henoch; Bang, Ole; Bjarklev, Anders Overgaard; Andersen, Peter E.; Broeng, Jes

\section{Published in:}

Conference on Lasers and Electro-Optics, 2005. (CLEO).

Link to article, DOI:

10.1109/CLEO.2005.202090

Publication date:

2005

Document Version

Publisher's PDF, also known as Version of record

Link back to DTU Orbit

Citation (APA):

Frosz, M. H., Bang, O., Bjarklev, A. O., Andersen, P. E., \& Broeng, J. (2005). Supercontinuum generation in photonic crystal fibers: The role of the second zero dispersion wavelength. In Conference on Lasers and ElectroOptics, 2005. (CLEO). (Vol. 2, pp. 1255-1257). [CWC1] IEEE. https://doi.org/10.1109/CLEO.2005.202090

\section{General rights}

Copyright and moral rights for the publications made accessible in the public portal are retained by the authors and/or other copyright owners and it is a condition of accessing publications that users recognise and abide by the legal requirements associated with these rights.

- Users may download and print one copy of any publication from the public portal for the purpose of private study or research.

- You may not further distribute the material or use it for any profit-making activity or commercial gain

- You may freely distribute the URL identifying the publication in the public portal 


\title{
Supercontinuum generation in photonic crystal fibers: The role of the second zero dispersion wavelength
}

\author{
Michael H. Frosz, Ole Bang, and Anders Bjarklev \\ Research Center COM, Technical University of Denmark, Building 345v, \\ DK-2800 Kgs. Lyngby, Denmark \\ mf@com.dtu.dk \\ Peter E. Andersen \\ Optics and Plasma Research Department, Risø National Laboratory, \\ Frederiksborgvej 399, DK-4000 Roskilde, Denmark \\ Jes Broeng \\ Crystal Fibre A/S, Blokken 84, DK-3460 Birkerød, Denmark
}

\begin{abstract}
We study supercontinuum generation in photonic crystal fibers with various distances between the two zero dispersion wavelengths. Controllable generation of a red-shifted, nearly Gaussian shaped spectrum with a $3-\mathrm{dB}$ bandwidth of $200 \mathrm{~nm}$ is found. (C) 2005 Optical Society of America

OCIS codes: (190.4370) Nonlinear optics, fibers; (190.5530) Pulse propagation and solitons
\end{abstract}

Previous investigations of supercontinuum generation in photonic crystal fibers (PCFs) with two zero dispersion wavelengths (ZDWs) have provided two rather distinct explanations of the underlying physical mechanisms. Hilligsøe et al. [1] examined a PCF with a spacing of $165 \mathrm{~nm}$ between the two ZDWs and explained the supercontinuum as a result of self-phase modulation (SPM) and four-wave mixing (FWM). Genty et al. [2] investigated supercontinuum generation in PCFs with a spacing of more than $700 \mathrm{~nm}$ between the two ZDWs and found the most important mechanisms to be amplification of dispersive waves and soliton self-frequency shift (SSFS). In this work, we numerically examine supercontinuum generation in 5 different PCFs where the separation between the two ZDWs is between $165 \mathrm{~nm}$ and $700 \mathrm{~nm}$. By modifying the pitch $\Lambda$ and hole size $d$ of a triangular hole structure (see figure 1(a)) the lower ZDW remains constant at $\sim 780$ $\mathrm{nm}$, while the higher ZDW varies between $950 \mathrm{~nm}$ and $1650 \mathrm{~nm}$. The dispersion profiles of the fiber with $\Lambda=1.0 \mu \mathrm{m}$ and the fiber with $\Lambda=1.4 \mu \mathrm{m}$ are similar to the dispersion profile of the fiber examined by Hilligsøe et al. [1] and Genty et al. [2], respectively.

To focus this investigation on the influence of the higher ZDW, we have used the same input pulse parameters for all simulations: the pump wavelength is $\lambda_{0}=804 \mathrm{~nm}$, the FWHM is $T_{\mathrm{FWHM}}=13 \mathrm{fs}$, and the peak power is $P_{0}=15 \mathrm{~kW}$. Hilligsøe et al. [1] used a fiber length of $5 \mathrm{~cm}$. Genty et al. [2] used a fiber length up to 1.5 $\mathrm{m}$, but found that the continuum generation was complete after $50 \mathrm{~cm}$ of propagation. We have simulated

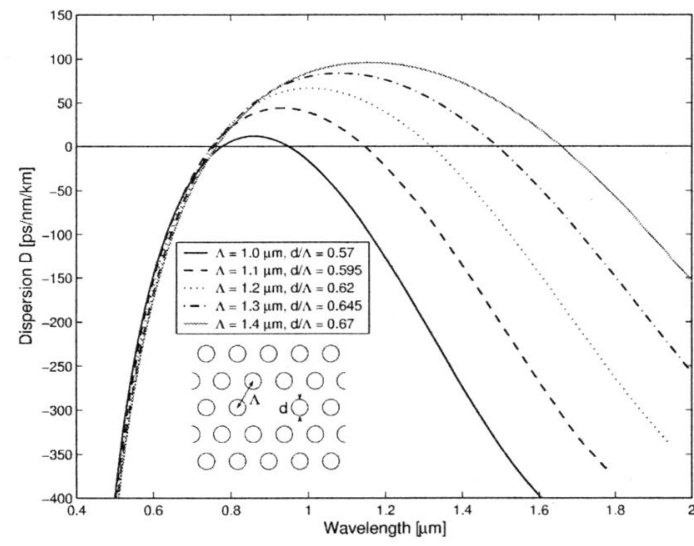

(a)

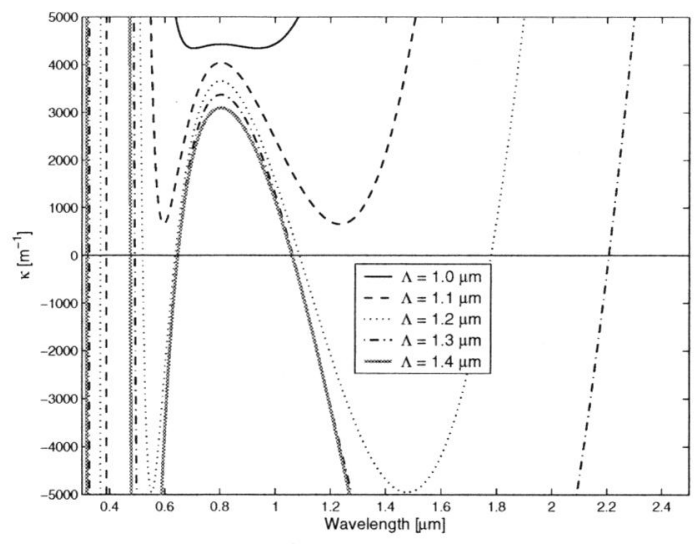

(b)

Fig. 1. (a): Calculated dispersion profiles for the 5 triangular PCFs. The pitch $\Lambda$ and the relative air-hole size $d / \Lambda$ are given in the inset. (b): Phase mismatch for direct degenerate FWM in the 5 PCFs for a peak power $P_{0}$ of $15 \mathrm{~kW}$ and pump wavelength $\lambda_{0}=804 \mathrm{~nm}$ 


\section{CWC1}
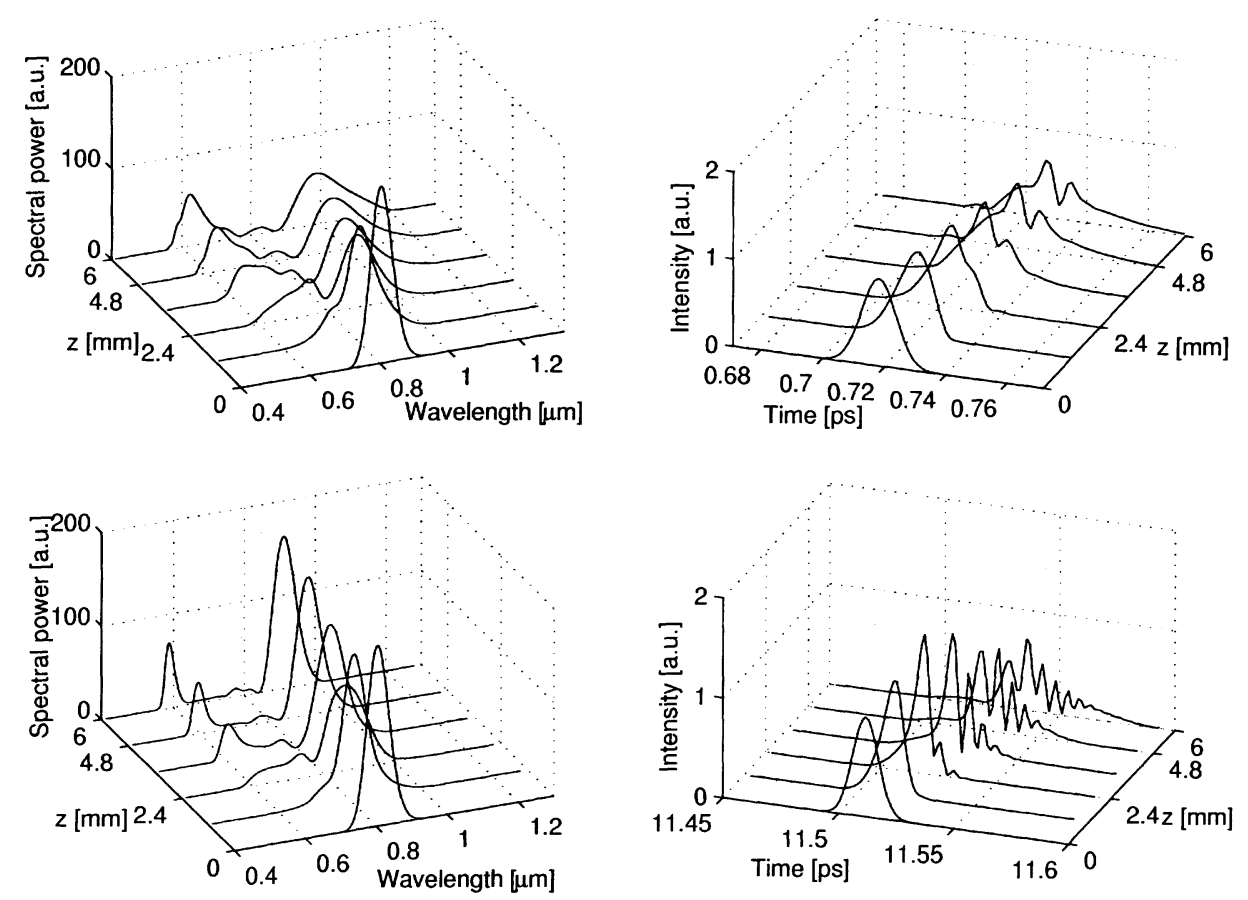

Fig. 2. Spectral (left) and temporal (right) evolution of the input pulse from 0 to $6 \mathrm{~mm}$ of propagation, in the fiber with $\Lambda=1.0 \mu \mathrm{m}$ (top) and $\Lambda=1.4 \mu \mathrm{m}$ (bottom). $2^{10}$ points were used in the simulation for the $\Lambda=1.0 \mu \mathrm{m}$ fiber, but the resulting spectrum is indistinguishable from the spectrum in figure 3 calculated with $2^{14}$ points.

propagation up to a length of $60 \mathrm{~cm}$, but here focus on the initial first $6 \mathrm{~mm}$.

The pulse propagation is simulated using the split-step Fourier method to solve the generalized nonlinear Schrödinger equation [3]. The model accounts for self-phase modulation, FWM, stimulated Raman scattering (SRS) and self-steepening. We simplify the investigation by assuming a polarization maintaining fiber pumped along one polarization axis, thus omitting cross-phase modulation. Our model includes the wavelength dependence of the effective core area $A_{\text {eff }}(\lambda)[4] . A_{\text {eff }}\left(\lambda=\lambda_{0}\right)$ varies between $1.38 \mu \mathrm{m}$ and $1.97 \mu \mathrm{m}$ for the fibers with $\Lambda=1.0 \mu \mathrm{m}$ and $\Lambda=1.4 \mu \mathrm{m}$, respectively. Losses are neglected in this work, but can be included in the model. The temporal resolution is $\Delta t=1.4 \mathrm{fs}$, the step length is $\Delta z=30 \mathrm{~nm}$, and $2^{14}$ points are used unless otherwise specified. For all simulations presented in this work the photon number was conserved within $0.012 \%$.

Figure 1(b) shows the phase mismatch for direct degenerate FWM for the fibers investigated. The power dependent phase mismatch is given as $\kappa=\Delta k+2 \gamma P_{0}$ [3], where $\Delta k$ is the combined linear phase mismatch from waveguide $\left(\Delta k_{W}\right)$ and material $\left(\Delta k_{M}\right)$ dispersion; $\gamma=n_{2} \omega_{0} /\left(c A_{\text {eff }}\right)$ is the nonlinear parameter. For a single-mode fiber $\Delta k_{W}=0$, and $\Delta k_{M}=\Omega^{2} \beta_{2}+(2 / 4 !) \Omega^{4} \beta_{4}+(2 / 6 !) \Omega^{6} \beta_{6}+\ldots$, where $\Omega$ is the frequency shift from the pump in the FWM process, and $\beta_{n}$ is the n'th order dispersion at $\lambda_{0}$ [3]. The FWM energy transfer from the pump is most efficient for $\kappa=0$, but the process has gain, given by $g=\sqrt{\left(\gamma P_{0}\right)^{2}-(\kappa / 2)^{2}}$, as long as $|\kappa|<2 \gamma P_{0}[3]$. Hilligsøe et al. found that SPM broadens the spectrum at the beginning of the fiber, followed by FWM when the peak power has dropped sufficiently to allow phase matching. The FWM transfers power out of the anomalous dispersion region [1]. For the fibers with $\Lambda=1.1-1.4 \mu \mathrm{m}$ we expect from figure 1(b) that FWM initially transfers pump energy to the first Stokes $(1000-1150 \mathrm{~nm})$ and anti-Stokes wavelengths $(600-650 \mathrm{~nm})$.

Figure 2 shows the pulse propagation during the first $6 \mathrm{~mm}$ in the fibers with $\Lambda=1.0 \mu \mathrm{m}$ and $\Lambda=1.4$ $\mu \mathrm{m}$, respectively. It is seen that for both fibers, some of the pump energy is blue-shifted to around $600 \mathrm{~nm}$. This can be attributed to two physical processes: FWM [1] and amplification of dispersive waves [2]. Both 


\section{CWC1}

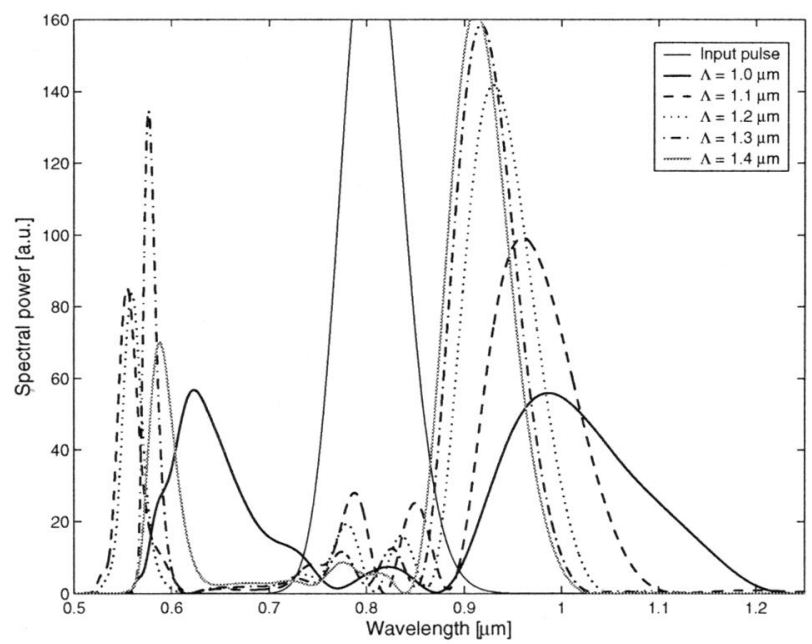

Fig. 3. Spectra after $6 \mathrm{~mm}$ of propagation. The input spectrum is indicated as a thin solid black line.

processes require phase matching between a pump and the blue-shifted wave, but FWM implies that a Stokes component is built up simultaneously. A red-shifted component is indeed seen for both fibers, which could be attributed to FWM and Raman scattering of the pump. However, we also performed simulations with all the dispersion terms set to zero, thus removing the possibility for FWM $(g=0$ for all $\lambda)$ and amplification of dispersive waves. A red-shift of the pump similar to the one seen in figure 2 was observed in the resulting spectra, without any significant power around $600 \mathrm{~nm}$. This strongly indicates that the red-shift of the pump is mainly due to soliton self-frequency shift, i.e. Raman scattering.

Figure 3 compares the calculated spectra for each fiber after $6 \mathrm{~mm}$ of propagation. It is seen that even for such a short propagation length, the resulting spectra are quite different. For all of the fibers SRS and amplification of dispersive waves has transferred most of the power from the pump to two distinct peaks, one lower and one higher in wavelength than the input spectrum. It is noteworthy that for the $\Lambda=1.0 \mu \mathrm{m}$ fiber the red-shifted peak centered at $\sim 1 \mu \mathrm{m}$ is nearly Gaussian in shape and has a $3 \mathrm{~dB}$ bandwidth of $\sim 200$ nm.

In our contribution we examine the continued propagation along the fibers and how the higher ZDW can be used to control the spectral location of the red-shifted peak, and the width and shape of the whole spectrum at the fiber output.

\section{References}

1. K. M. Hilligsøe, T. V. Andersen, H. N. Paulsen, C. K. Nielsen, K. Mølmer, S. Keiding, R. Kristiansen, K. P. Hansen, and J. J. Larsen, "Supercontinuum generation in a photonic crystal fiber with two zero dispersion wavelengths," Opt. Express 12(6), 1045-1054 (2004).

2. G. Genty, M. Lehtonen, H. Ludvigsen, and M. Kaivola, "Enhanced bandwidth of supercontinuum generated in microstructured fibers," Opt. Express 12(15), 3471-3480 (2004).

3. G. P. Agrawal, Nonlinear Fiber Optics, 3rd ed. (Academic Press, San Diego, CA, USA, 2001).

4. J. Lægsgaard, N. A. Mortensen, and A. Bjarklev, "Mode areas and field-energy distribution in honeycomb photonic bandgap fibers," J. Opt. Soc. Am. B 20(10), 2037-2045 (2003). 